\title{
O conceito de número na Educação Matemática: uma incursão em pesquisas com crianças
}

\section{The concept of number in Mathematics Education: a study in research with children}

\author{
Lutieli Rodrigues Botelho ${ }^{1}$ \\ Universidade Federal do Pampa (UNIPAMPA), Jaguarão, RS, Brasil \\ https://orcid.org/0000-0002-0600-7428, $\Theta$ http://lattes.cnpq.br/1428630152652865 \\ João Carlos Pereira de Moraes² \\ Universidade Federal do Pampa (UNIPAMPA), Jaguarão, RS, Brasil \\ https://orcid.org/0000-0001-9513-018X, 9 http://lattes.cnpq.br/5624816456388130
}

\begin{abstract}
Resumo: Essa pesquisa objetiva analisar como o debate sobre o conceito de número tem sido abordado em pesquisas com crianças de Educação Infantil e anos iniciais do Ensino Fundamental, a partir de seus objetivos, metodologias de pesquisa, ensino e inferências. Nesse sentido, produzimos um levantamento em três bancos de dados: BDTD, CTD e ENEM, o que suscitou quinze estudos. A análise dos dados foi feita a partir da metodologia de Análise de Conteúdo (BARDIN, 2011). A partir da análise, levantamos que as pesquisas concentram-se na região Sudeste, em sua maioria são dissertações e há um indício de crescimento dos estudos nos últimos cinco anos. Além disso, quanto aos objetivos de pesquisa, notamos que mesmo as pesquisas envolverem sujeitos crianças, há influência de discussões no campo de ensino. No que se refere às metodologias de ensino e pesquisa, o uso de sequência de atividades e o estudo de caso tem a sua maior evidência. Já no que tange as inferências, notamos que muitas ainda são genéricas e com poucas considerações sobre o conceito de número.
\end{abstract}

Palavras-chave: conceito de número; crianças; Estado de Conhecimento; Educação Matemática.

Abstract: This research aims to analyze how the debate on the concept of number has been approached in research with children from early childhood education and early years of elementary school; based on its objectives, research and teaching methodologies and inferences. In this sense, we produced a survey in three databases: BDTD, CTD and ENEM, which led to fifteen studies. Data analysis was performed using Content Analysis methodology (BARDIN, 2011). While analyzing the material, we found out that the research is concentrated in the Southeast region, they are, in most part, dissertations, and there is an indication of growth in these studies in the last five years. In addition, regarding the research objectives, we observed that even though the research involves young subjects such as children, there is an influence of discussions in the teaching field. With regard to teaching and research methodologies, the use of sequence of activities and case study have the greatest role. Concerning the inferences, we noticed that many are still generic and with few considerations with respect to the concept of number.

Keywords: number concept; children; State of Knowledge; Mathematics Education.

Data de submissão: 23 de Fevereiro de 2021.

Data de aprovação: 27 de Junho de 2021.

\footnotetext{
1 Currículo sucinto: Licenciada em Pedagogia e mestranda do Programa de Educação da Universidade Federal do Pampa. Contribuição de autoria: Administração do Projeto, Análise Formal, Conceituação, Curadoria de Dados, Escrita - Primeira Redação, Investigação, Metodologia. Contato: lutiele.luna@gmail.com.

2 Currículo sucinto: Licenciado em Matemática pela Universidade Estadual do Norte do Paraná, Licenciado em Pedagogia pela Universidade Estadual de Maringá, Mestre em Educação Científica e Tecnológica pela Universidade Federal de Santa Catarina, Doutor em Educação pela Universidade de São Paulo. Docente da Universidade Federal do Pampa. Contribuição de autoria: Administração do Projeto, Escrita - Revisão e Edição, Supervisão, Validação e Visualização. Contato: joaomoraes@unipampa.edu.br.
} 


\section{Introdução}

Neste estudo, realizamos uma revisão sistemática de literatura, visando levantar estudos relacionados ao conceito de número. Nesse sentido, consideramos este estudo um estado de conhecimento, como aponta Romanowski e Ens (2006).

Segundo os pesquisadores, o estado do conhecimento diferencia-se do estado da arte por abordar um grupo de setores mais restritos de publicações a respeito de um determinado tema estudado (ROMANOWSKI; ENS, 2006). Embora mais limitado, o estado do conhecimento não impede a visualização de elementos constituintes sobre um determinado assunto, bem como suas lacunas e possibilidades.

Mediante ao exposto, o objetivo desse estado de conhecimento consiste em analisar como o debate sobre o conceito de número tem sido abordado em pesquisas com crianças de Educação Infantil e anos iniciais do Ensino Fundamental, a partir de seus objetivos, metodologias de pesquisa e ensino e inferências.

A partir disso, elaboramos as seguintes etapas da pesquisa: (1) Levantamento em bases de dados definidas a priori; (2) Seleção de trabalhos relacionados com a temática de pesquisa; (3) Análise e classificação dos trabalhos quanto ao ano, natureza e região do país; (4) Análise dos objetivos, metodologias e inferências dos trabalhos. Essa sequência é apresentada de maneira mais descritiva abaixo.

\section{Aspectos metodológicos da composição do Estado de Conhecimento}

Nesta seção, abordamos a revisão sistemática produzida como forma de organizar e produzir o estado do conhecimento relativo ao trabalho com conceito de número na Educação Infantil e anos iniciais do Ensino Fundamental.

\subsection{Metodologia da revisão}

Inicialmente para a pesquisa, elegemos duas bases de dados: (1) Biblioteca Digital de Teses e Dissertações (BDTD) e o Catálogo de Teses e Dissertações da Capes (CTD). Nesse momento, utilizamos os descritores "conceito de número" AND "Educação Matemática". Ao total, encontramos cinquenta e nove (59) produções nas duas bases. Neste grupo e a partir da leitura de títulos e resumos, realizamos a seleção daqueles com sujeitos de pesquisa crianças da Educação Infantil e/ou alunos dos anos iniciais do Ensino Fundamental, o que configurou num total de doze (12) dissertações e teses.

Como forma de complementar e de ampliar o corpus de análise, levantamos pesquisas sobre o conceito de número nos últimos dez anos do Encontro Nacional de Educação Matemática - ENEM, do X ao XIII. A busca foi realizada a partir do descritor "conceito de número", apenas nas 
comunicações orais, uma vez que acreditamos que nelas são encontradas as pesquisas sobre o assunto. Ao final da busca, encontramos somente três (3) artigos.

\subsection{Resultado da pesquisa}

A seguir, apresentamos a lista dos estudos encontrados a partir da pesquisa elencada anteriormente. Ao final, totalizamos quinze (15) trabalhos (dissertações, teses e artigos). Como mostra a classificação do Quadro 1, levantamos inicialmente as seguintes informações: natureza, título, autor e ano de publicação.

Quadro 1 - Trabalhos levantados

\begin{tabular}{|c|c|c|c|c|}
\hline Termo* & Natureza & Título & Autor & Ano \\
\hline $\mathrm{T} 1$ & Dissertação & $\begin{array}{l}\text { A aprendizagem do conceito de número de crianças do } \\
\text { Infantil V: interações com o flex memo }\end{array}$ & Belo & 2018 \\
\hline $\mathrm{T} 2$ & Dissertação & $\begin{array}{l}\text { A construção do conceito de número por uma aluna com } \\
\text { surdocegueira congênita }\end{array}$ & Aleixo & 2018 \\
\hline T3 & Dissertação & $\begin{array}{l}\text { O ensino do conceito de número: objetivações nas } \\
\text { proposições davydovianas e formalista moderna }\end{array}$ & Souza & 2013 \\
\hline $\mathrm{T} 4$ & Tese & O senso numérico da criança: formação e características & Ferrari & 2008 \\
\hline T5 & Dissertação & Número: o conceito a partir de jogos & Fonseca & 2005 \\
\hline T6 & Dissertação & $\begin{array}{l}\text { Investigações sobre números naturais e processos de ensino } \\
\text { e aprendizagem desse tema no início da escolaridade }\end{array}$ & Bonaldo & 2007 \\
\hline T7 & Dissertação & $\begin{array}{l}\text { A construção do número pela criança com deficiência } \\
\text { intelectual: a percepção entre diferentes ambientes escolares }\end{array}$ & Noleto & 2017 \\
\hline T8 & Tese & $\begin{array}{l}\text { Investigação da construção do número em LIBRAS: estudo } \\
\text { com crianças surdas }\end{array}$ & Madalena & 2017 \\
\hline T9 & Tese & $\begin{array}{l}\text { Uma abordagem multissensorial para o desenvolvimento do } \\
\text { conceito de número natural em indivíduos com síndrome de } \\
\text { down }\end{array}$ & Yokoyama & 2012 \\
\hline T10 & Dissertação & $\begin{array}{l}\text { Representação semiótica: uma perspectiva para a } \\
\text { construção do conceito de número na educação infantil }\end{array}$ & Dinis & 2018 \\
\hline T11 & Dissertação & $\begin{array}{l}\text { Uma proposta de software de educação matemática para } \\
\text { educação infantil }\end{array}$ & Boscariol & 2004 \\
\hline $\mathrm{T} 12$ & Dissertação & $\begin{array}{l}\text { Uma proposta para utilização do computador no processo de } \\
\text { ensino e aprendizagem dos primeiros números do sistema } \\
\text { hindu-arábico }\end{array}$ & Silva & 1998 \\
\hline T13 & Artigo & $\begin{array}{l}\text { Percepções de crianças do } 1^{\circ} \text { ano do Ensino Fundamental } \\
\text { sobre o conceito de números }\end{array}$ & $\begin{array}{l}\text { Guillen e } \\
\text { Sousa }\end{array}$ & 2010 \\
\hline T14 & Artigo & $\begin{array}{l}\text { Análises no processo de construção do conceito de número } \\
\text { de alunos do } 1^{\circ} \text { ano do Ensino Fundamental em uma prática } \\
\text { colaborativa }\end{array}$ & $\begin{array}{l}\text { Santos, } \\
\text { Manfredo } \\
\text { e Costa }\end{array}$ & 2019 \\
\hline T15 & Artigo & $\begin{array}{l}\text { Correspondência um a um: uma situação desencadeadora } \\
\text { de aprendizagem voltada ao conceito de número }\end{array}$ & $\begin{array}{l}\text { Binsfeld, } \\
\text { Golin e } \\
\text { Klein }\end{array}$ & 2019 \\
\hline
\end{tabular}

*Observação: para otimizar a análise dos dados, cada trabalho recebeu a nomenclatura T e um número, conforme a ordem levantada.

Fonte: Dados da pesquisa (2020).

Com os dados coletados, elaboramos uma análise mais aprofundada de cada estudo, sendo essa sistemática apresentada a seguir. 


\subsection{Análise dos dados}

Os trabalhos acima elencados foram analisados em dois momentos. Primeiramente, analisamos os aspectos de modo geral, levando em consideração o ano, natureza e região do país. Em segundo momento, a análise ocorreu a partir da metodologia Análise de Conteúdo. Segundo Bardin (2011), a Análise de Conteúdo é um processo de análise que classifica em categorias e, ao longo do tempo, permite que se realizem inferências, deixando de ser apenas um ato descritivo sobre os dados.

Como elemento de análise, utilizaram-se as seguintes perguntas norteadoras como categorias a priori:

- P1: Qual é o objetivo do trabalho de pesquisa?

- P2: Quais as abordagens metodológicas usadas para o ensino do conceito de número?

- P3: Quais as metodologias de pesquisa utilizadas nos trabalhos de pesquisa?

- P4: Quais as principais inferências levantadas nos estudos?

A partir dessas perguntas, analisamos os dados em cada trabalho até então encontrado na revisão sistemática, dividindo em quatro categorias: (1) objetivos de pesquisa; (2) abordagens metodológicas de ensino; (3) abordagens metodológicas na pesquisa; e (4) inferências levantadas.

\section{Resultados e discussões}

Nesta seção, realizamos a análise dos aspectos gerais e das questões norteadoras, a partir da leitura dos trabalhos.

\subsection{Aspectos gerais}

Entre os quinze trabalhos elencados anteriormente, levaremos em consideração alguns aspectos mais gerais como: região, natureza e ano. No Quadro 2, apresentamos as regiões nas quais cada trabalho foi publicado.

Quadro 2 - Trabalhos por Regiões de publicação

\begin{tabular}{|c|c|c|}
\hline Região & Quantidade & Trabalhos \\
\hline Norte & 1 & T13 \\
\hline Nordeste & 1 & T1 \\
\hline Centro-Oeste & 3 & T7, T14 e T15 \\
\hline Sudeste & 8 & T4, T5, T6, T8, T9, T10, T11, T12 \\
\hline Sul & 2 & T2 e T3 \\
\hline
\end{tabular}

Fonte: Dados da pesquisa (2020).

A partir dessa busca, percebemos que existem produções em todas as regiões brasileiras, contudo encontramos um número maior de trabalhos publicados na região Sudeste (8). Para 
Fernandes, Moraes e Pereira (2020), essa diferenciação ocorre em decorrência da concentração dos cursos de mestrado e doutorado na região Sudeste, bem como o alto número de pesquisadores.

No Quadro 3, distribuímos os trabalhos encontrados por sua natureza.

Quadro 3 - Natureza dos trabalhos encontrados

\begin{tabular}{|c|c|c|}
\hline Natureza & Quantidade & Trabalhos \\
\hline Dissertação & 9 & $\mathrm{~T} 1, \mathrm{~T} 2, \mathrm{~T} 3, \mathrm{~T} 5, \mathrm{~T} 6, \mathrm{~T} 7, \mathrm{~T} 10, \mathrm{~T} 11, \mathrm{~T} 12$ \\
\hline Tese & 3 & $\mathrm{~T} 4, \mathrm{~T} 8, \mathrm{e}$ T9 \\
\hline Artigo & 3 & $\mathrm{~T} 13, \mathrm{~T} 14$ e T15 \\
\hline
\end{tabular}

Fonte: Dados da pesquisa (2020).

A partir do levantamento, notamos que os trabalhos elencados são em sua maioria dissertações, totalizando nove (9) ao todo. Consideramos que o maior número de dissertações possa ser reflexo da aproximação da natureza deste tipo de pesquisa com a prática docente na Educação Básica, bem como o número de mestrados de cunho profissional no Brasil.

Já no Quadro 4, mostramos a separação dos estudos perante o ano de publicação de cada trabalho.

Quadro 4 - Ano de publicação dos trabalhos levantados

\begin{tabular}{|c|c|c|}
\hline Ano & Quantidade & Trabalhos \\
\hline 1998 & 1 & T12 \\
\hline 2004 & 1 & T11 \\
\hline 2005 & 1 & T5 \\
\hline 2007 & 1 & T6 \\
\hline 2008 & 1 & T4 \\
\hline 2010 & 1 & T13 \\
\hline 2012 & 1 & T9 \\
\hline 2013 & 1 & T3 \\
\hline 2017 & 2 & T7 e T8 \\
\hline 2018 & 3 & T1, T2 e T10 \\
\hline 2019 & 2 & T14 e T15 \\
\hline
\end{tabular}

Fonte: Dados da pesquisa (2020).

Nos bancos de dados, encontramos trabalhos num período de mais de vinte (20) anos, entre 1998 e 2019. Se realizarmos o agrupamento dos anos por quinquênio, perceberemos o aumento de estudos no período de 2016-2020, principalmente no ano de 2018, com três (3) estudos. Nesse sentido, consideramos a possibilidade de uma preocupação maior nos últimos anos com a aprendizagem do conceito de número na Educação Infantil e nos anos iniciais do Ensino Fundamental. 
Nesta seção, percebemos por meio da análise realizada que os trabalhos estão concentrados na região Sudeste e são em sua maioria dissertações. A seguir, apresentamos nossas análises a partir das perguntas norteadoras.

\subsection{Categoria 1: Objetivos de pesquisas}

$\mathrm{Na}$ primeira categoria ressaltamos os objetivos de pesquisa dos trabalhos encontrados. Para melhor organização, construímos um quadro dividindo os objetivos em dois grupos: (1) o primeiro grupo é dos trabalhos com objetivo voltados para o ensino e (2) o segundo com os objetivos voltados para a aprendizagem dos alunos.

Quadro 5 - Objetivos dos trabalhos

\begin{tabular}{|c|c|c|}
\hline Grupo & Quantidade & Trabalhos \\
\hline Objetivos de ensino & 8 & $\mathrm{~T} 1, \mathrm{~T} 3, \mathrm{~T} 5, \mathrm{~T} 10, \mathrm{~T} 11, \mathrm{~T} 12, \mathrm{~T} 14 \mathrm{e} \mathrm{T} 15$ \\
\hline Objetivos de aprendizagem & 7 & $\mathrm{~T} 2, \mathrm{~T} 4, \mathrm{~T} 6, \mathrm{~T} 7, \mathrm{~T} 8, \mathrm{~T} 9 \mathrm{e} \mathrm{T} 13$, \\
\hline
\end{tabular}

Fonte: Dados da pesquisa (2020).

No primeiro grupo, objetivos de ensino, temos aqueles trabalhos mais direcionados para o ensino do conceito de números, bem como o foco nas metodologias de ensino.

Neste grupo, temos aqueles voltados para o âmbito geral:

T3: Analisamos duas propostas de ensino: a davydoviana e a formalista moderna, no que se refere à introdução do conceito de número, no primeiro ano do Ensino Fundamental. (SOUZA, 2013, p. 8, grifo nosso).

T5: Investigar uma nova abordagem para o conceito de número, com vistas a buscar nela elementos que favoreçam o ensino e consequentemente a aprendizagem. (FONSECA, 2005, p. 9, grifo nosso).

T14: Investigar processos cognitivos na construção do conceito de número de alunos do $1^{\circ}$ ano do Ensino Fundamental por meio de um trabalho colaborativo com os professores. (SANTOS; MANFREDO; COSTA, p. 7, grifo nosso).

A partir dos objetivos, observamos que as propostas são mais genéricas. Enquanto T3 compara duas propostas de ensino, a davydoviana e a formalista moderna, T5 procura abordagens que favoreçam o ensino do conceito de número e T14 enfatiza os processos cognitivos para pensar uma formação docente colaborativa.

No interior do primeiro grupo ainda, estão àqueles trabalhos voltados para as questões metodológicas, como:

T1: Analisar a contribuição da interação com os jogos de Memória, Segredo da Caixa e Batalha proporcionados pelo Flex memo para a ampliação do conceito de número de crianças do infantil V. (BELO, 2018, p. 10, grifo nosso).

T11: Desenvolver um software de educação matemática para educação infantil com a finalidade de propiciar a construção do número pela criança. (BOSCARIOL, 2004, p. 10, grifo nosso).

T12: Apresentar o desenvolvimento e os resultados de uma pesquisa, cujo foco de interesse tem sido a elaboração de meios voláteis para computadores 
(softwares), que possam auxiliar o processo de ensino e aprendizagem do sistema de numeração hindu-arábico, em crianças na fase de alfabetização. (SILVA, 1998, p. 9, grifo nosso).

T15: Relatar uma situação desencadeadora de aprendizagem (SDA) envolvendo o conceito de número, desenvolvida por participantes do projeto Clube de Matemática da Universidade Federal de Santa Maria (UFSM), em uma turma de $1^{\circ}$ ano dos anos iniciais do Ensino Fundamental. (BINSFELD; GOLIN; KLEIN, 2019, p. 10, grifo nosso).

T10: Investigar o papel do registro de representação semiótica na construção do conceito de número por crianças da educação infantil. (DINIS, 2018, p. 12, grifo nosso).

A partir da leitura dos objetivos, notamos que estes estão mais voltados para os procedimentos metodológicos. Com esses, visualizamos o interesse em elucidar como certas práticas metodológicas podem colaborar com o ensino de números para crianças da Educação Infantil e anos iniciais do Ensino Fundamental. Entre as propostas de intervenção estão: jogos (T1), softwares (T11, T12), situação desencadeadora de aprendizagem (T15) e os registros de representação semiótica (T10).

Neste primeiro grupo, consideramos que, mesmo enfatizando as pesquisas com crianças, os estudos intentam atingir a formação de professores que ensinam matemática, trazendo possibilidades de intervenção e reflexão para outros docentes que possam ler e analisar as práticas desenvolvidas.

No segundo grupo, denominado objetivos de aprendizagem, vemos aqueles objetivos mais voltados para a aprendizagem. Semelhante ao anterior, há aqueles voltados para as questões mais gerais, tais como:

T4: Investigar a formação do conceito de número na criança. (FERRARI, 2008, p. 5 , grifo nosso).

T6: Investigar o ensino e aprendizagem de números naturais, buscando identificar semelhanças e diferenças entre os resultados e indicações de pesquisas sobre a construção do conceito de números pelas crianças. (BONALDO, 2007, p. 8, grifo nosso).

T13: Apresentar os resultados de um estudo, realizado em 2008, o qual tinha como foco a análise das percepções de crianças sobre o conceito numérico. (GUILLEN; SOUSA, 2010, p. 7, grifo nosso).

Os objetivos trazidos acima, nos mostram uma visão metodológica mais voltada à aprendizagem dos alunos, porém não oferecem indícios sistemáticos de intervenção. Notamos alguns pontos levantados: formação do conceito de números (T4), ensino e aprendizagem dos números naturais (T6) e percepções das crianças (T13).

No segundo grupo, também, encontramos trabalhos voltados para a aprendizagem de crianças com deficiência, como:

T2: Investigar a construção do conceito de número por uma aluna com surdocegueira congênita. (ALEIXO, 2018, p. 2, grifo nosso). 
T7: Analisar os processos mentais associados à construção do número desenvolvidos na sala de aula e na sala de recursos por uma criança com deficiência intelectual em fase de alfabetização. (NOLETO, 2017, p. 9, grifo nosso).

T8: Investigar a aquisição de conhecimentos numéricos de crianças surdas que utilizam a Língua Brasileira de Sinais, como primeira Língua, a partir da perspectiva da Psicologia do Desenvolvimento Cognitivo. (MADALENA, 2017, p. 12, grifo nosso).

T9: Este estudo considera a evolução do conceito de número natural, e mais especificamente a quantificação de conjuntos discretos de até 10 elementos, por crianças e adolescentes com síndrome de Down. (YOKOYAMA, 2012, p. 11, grifo nosso).

As pesquisas citadas acima levantam os processos de aprendizagem de crianças com deficiências, tais como: surdocegueira (T2), deficiência intelectual (T7), surdez (T8) e síndrome de Down (T9). Consideramos que uma possível escolha destes grupos para as pesquisas com o conceito de número refere-se à necessidade de pensarmos práticas inclusivas em Educação Matemática, bem como investigar os processos cognitivos de crianças com deficiência e suas possíveis variações relativas ao descrito nas teorias psicológicas da área.

\subsection{Categoria 2: Quais as abordagens metodológicas usadas para o ensino do conceito de número?}

Nesta seção foram investigados e separados os trabalhos através de seus procedimentos metodológicos. Criamos seis grupos conforme as abordagens de ensino nos estudos: jogos, tecnologia, análise de materiais e documentos, atividades, testes e história virtual do conceito, conforme quadro abaixo.

Quadro 6 - Abordagens metodológicas utilizadas

\begin{tabular}{|c|c|c|}
\hline Abordagem & Quantidade & Trabalhos \\
\hline Jogos & 3 & T1, T5, e T10 \\
\hline Tecnologia & 2 & T11 e T12 \\
\hline Análise de materiais e Documentos & 2 & T3 e T6 \\
\hline Atividades & 5 & T2, T4, T7, T9 e T14 \\
\hline Testes & 2 & T8 e T13 \\
\hline História virtual do conceito & 1 & T15 \\
\hline
\end{tabular}

Fonte: Dados da pesquisa (2020).

No grupo 1, jogos, os estudos focaram na utilização de jogos para produzir a intervenção com os alunos. Em T1 foi utilizado o Flex memo, mais especificamente os jogos Memória, Segredo da Caixa e Batalha. T5 apoiou-se no jogo Hackenbush para compor a pesquisa. Por sua vez, T10 utilizou-se dos jogos ressignificados, em que os jogos serviram tanto para intervenção quanto para a análise dos dados. 
Conforme Grando (1995), os jogos trazem vantagens para a prática pedagógica, como desenvolvimento de conceitos de difícil compreensão, participação ativa dos alunos e motivação nas aulas. Nesse sentido, as pesquisas que utilizam-se deste recurso podem oportunizar maiores socializações e debates sobre o pensamento matemático das crianças.

No grupo 2, tecnologia, foram encontrados dois trabalhos que desenvolveram meios que envolvessem as tecnologias como suporte pedagógico. Em T11, desenvolveu-se um software com a intenção de auxiliar os alunos na construção do conceito de número, enquanto que T12 realizou uma sequência de atividades computadorizadas para auxiliar na aprendizagem dos primeiros números pelas crianças.

Segundo Moraes (2017), as tecnologias na Educação Matemática tornam-se mais potentes quando o docente tem compreensão da perspectiva epistemológica que envolve o seu entendimento do ensino, bem como, do papel da tecnologia nesse contexto. Perante a perspectiva deste pesquisador, notamos que há um processo consciente de inserção da tecnologia para o ensino de número, tanto em T11 quanto em T12.

No grupo 3, análise de materiais e documentos, encontramos dois trabalhos (T3 e T6). Ambos os estudos envolvem a análise de livros didáticos e análise dos cadernos de alunos para a obtenção de inferências na sua pesquisa. Embora não realizassem intervenção diretamente com alunos, os estudos consideram os mesmos como sujeitos de pesquisas em seus trabalhos.

Já no grupo 4, denominado de atividades, é aquele com o maior número de trabalhos (T2, T4, T7, T9, T14). Esse grupo reuniu atividades que não foram categorizados com nenhuma metodologia específica. Encontramos aqui, a aplicação de atividades pautadas nos processos mentais estipulados por Lorenzatto (2008) (T2), atividades inspiradas nos experimentos de Dehaene (1997) (T4) e atividades para compreender os processos do conceito de número (T7, T9, T14). Nesse grupo, percebemos a forte influência dos aspectos da psicologia no ensino do conceito de número, bem como aplicação e adaptação de experimentos didáticos.

No grupo 5, testes, dois trabalhos foram categorizados (T8, T13). Enquanto T8 propõe testes de habilidades para o conceito de número com alunos surdos que utilizam a Língua Brasileira de Sinais como sua primeira língua, T13 apresenta testes para suscitar percepções de crianças do primeiro ano do Ensino Fundamental.

No último grupo, nomeado como História virtual do conceito, traz apenas T15, que visa à criação de histórias virtuais para o ensino do conceito de número, no sentido de produzir contextos para os alunos refletirem sobre a temática. 


\subsection{Categoria 3: metodologias de pesquisa utilizadas nos trabalhos}

Nesta seção, dividimos as metodologias de pesquisa dos trabalhos analisados em três categorias, sendo elas: (1) metodologias categorizadas; (2) metodologias não categorizadas; e (3) pesquisas que não apresentaram claramente a sua metodologia.

Quadro 7 - Metodologias de pesquisa

\begin{tabular}{|c|c|c|c|}
\hline Metodologia da pesquisa & Metodologia de pesquisa & Quantidade & Trabalhos \\
\hline \multirow{3}{*}{ Metodologia categorizada } & Pesquisa-ação & 1 & T14 \\
\cline { 2 - 4 } & Estudo de caso & 5 & T2, T4, T7, T8, T13 \\
\cline { 2 - 4 } & Bibliográfica e documental & 2 & T3, T6 \\
\hline $\begin{array}{c}\text { Metodologia não } \\
\text { categorizada }\end{array}$ & Descrição de etapas & 5 & T1, T9, T10, T11, T12 \\
\hline \multicolumn{2}{|c|}{ Não apresenta claramente } & 1 & T5 \\
\hline
\end{tabular}

Fonte: Dados da pesquisa (2020).

No primeiro grupo, denominado metodologias categorizadas, tem a subdivisão em três subcategorias que são: pesquisa-ação, estudo de caso e bibliográfica e documental. A primeira subcategoria, encontramos T14 que se utiliza da pesquisa-ação, apoiando num grupo colaborativo de docentes para realizar sua intervenção sobre o ensino de números com as crianças.

A segunda subcategoria apresenta trabalhos que utilizam da metodologia do estudo de caso (T2, T4, T7, T8, T13). Todos se apropriam desta abordagem por realizarem suas pesquisas com uma única turma de alunos da Educação Básica, considerando, assim, que a unicidade contextual de uma sala permite pensá-la como um caso para intervenção, passível de produzir generalizações mais amplas sobre o objeto de pesquisa.

$\mathrm{Na}$ terceira subcategoria, encontram-se as pesquisas bibliográfica e documental (T3, T6), que envolvem as metodologias de análise de documentos bibliográficos, curriculares, cadernos de alunos e manual do professor. A concepção de tais pesquisas consiste de que os materiais permitem levantar novas considerações para a prática pedagógica com o conceito de número.

No segundo grupo, metodologias não categorizadas, apresentamos aquelas que definem metodologias para a intervenção, que não necessariamente associam-se a análise dos dados. Este grupo prioriza a descrição das etapas de intervenção do que a associação com metodologias específicas (T1, T9, T10, T11, T12). Os estudos do grupo refletem o entendimento que a descrição sequencial de passos da pesquisa é essencial para o desenvolvimento teórico de uma produção científica.

Por fim, o último grupo denomina-se não apresenta claramente a sua metodologia de trabalho, composto apenas por T5. A partir da leitura dos pesquisadores, não encontramos descrições detalhadas que pudessem embasar outra classificação. 


\subsection{Categoria 4: principais inferências dos estudos}

Nesta seção, categorizamos as inferências dos trabalhos, dividindo-as em: (1) inferências genéricas; (2) inferências específicas; e (3) inferências incompletas. Torna-se válido ressaltar que esta categorização pautou-se nos resumos e considerações finais dos estudos.

Quadro 8 - Inferências dos estudos

\begin{tabular}{|c|c|c|}
\hline Inferências & Quantidade & Trabalhos \\
\hline Inferências Genéricas & 5 & T1, T2, T4, T7 e T13 \\
\hline Inferências Específicas & 5 & T3, T8, T9, T10 e T15 \\
\hline Inferências incompletas & 5 & T5, T6, T11, T12 e T14 \\
\hline
\end{tabular}

Fonte: Dados da pesquisa (2020).

No primeiro grupo de inferências, elencamos aquelas que consideramos genéricas:

T1: Ampliaram seus conhecimentos a respeito do conceito de número. (BELO, 2018, p. 85).

T2: Construção de novos conhecimentos. (ALEIXO, 2018, p. 100).

T4: Conceito de número é basilar na constituição dos conceitos da Matemática. (FERRARI, 2008, p. 91).

T7: Criança insere-se no seu lugar como sujeito de suas aprendizagens e de seu desenvolvimento. (NOLETO, 2017, p. 125).

T13: Contribuição com os nexos conceituais. (GUILLEN; SOUSA, 2010, p. 100).

Perante os excertos acima, visualizamos que todas as pesquisas apresentam que modificações positivas ocorreram nos processos de aprendizagem, tanto no que se refere à relação entre alunos e o conceito de número - ampliação (T1) e novos (T2), por exemplo - quanto do próprio desenvolvimento da criança - sujeito de sua aprendizagem (T7).

No grupo de inferências específicas, há explicações mais detalhadas dos resultados obtidos ao longo da pesquisa. Podemos ver as seguintes considerações:

T3: As duas propostas de ensino se distinguem, em método e conteúdo, que tem como consequência: o desenvolvimento do conhecimento empírico, na proposição formalista, e do conhecimento teórico, na proposição davydoviana. (SOUZA, 2013, p. 5, grifo nosso).

T8: Os resultados mostram a influência da escolaridade na construção das habilidades numéricas, assim como do tempo de exposição e frequência de uso da Língua de Sinais. Os dados também apontam associações existentes entre habilidades de recitação e de contagem com desempenhos em linguagem compreensiva e expressiva e com velocidade de processamento, inteligência nãoverbal e memória de trabalho. (MADALENA, 2017, p. 110, grifo nosso).

T9: Um aspecto das atividades que parecia particularmente importante para permitir que os participantes fossem além da utilização de procedimento de contagem mecanizada foi a presença de recursos multissensoriais que os participantes poderiam usar para verificar e corrigir suas próprias estratégias. (YOKOYAMA, 2012, p. 98, grifo nosso).

T10: Os resultados observados indicaram a utilização da representação da língua materna como ponto de partida para a apresentação do objeto matemático, 
como formação das primeiras representações e transformação em outro registro dentro do mesmo sistema semiótico (operações de tratamento). Nessa perspectiva, as representações semióticas contribuíram para a interiorização das representações mentais (noésis) que, por meio das relações estabelecidas, possibilitaram a apreensão conceitual do objeto matemático numa dada interação. (DINIS, 2018, p. 100, grifo nosso).

T15: Percebemos que as crianças se envolveram na situação, chegando a uma síntese da solução coletiva, aproximando-se do método de controle de variação de quantidades utilizado historicamente. (BINSFELD; GOLIN; KLEIN, 2019, p. 80, grifo nosso).

No grupo, percebemos inferências que avaliam as práticas de pesquisas e os seus efeitos na aprendizagem. Com exceção de T8, que associa tempo de escolaridade, habilidades numéricas e habilidades de linguagem de crianças surdas, as demais apontam impactos e benefícios de propostas metodológicas de ensino ou de recursos educacionais para o conceito de número. Nos escritos, observamos que diferentes abordagens teórico-metodológicas permitem a criação e a elaboração de diferentes produções conceituais sobre o pensamento numérico.

No grupo inferências incompletas, notamos que os trabalhos não trazem diferenciações e pormenores sobre o conceito de número. T5 e T6 descrevem como foi o processo de pesquisa. T11 e T12 suscitam o potencial, de modo geral, de práticas interativas com tecnologia e a necessidade de novas práticas com a metodologia. Por fim, T14 ressalta que a pesquisa ainda está em andamento, sem conclusões definitivas.

\section{Considerações finais}

Essa pesquisa teve por objetivo analisar como o debate sobre o conceito de número tem sido abordado em pesquisas com crianças de Educação Infantil e anos iniciais do Ensino Fundamental, a partir de seus objetivos, metodologias de pesquisa e ensino e inferências. Nesse sentido, produzimos um levantamento em três bancos de dados: BDTD, CTD e ENEM, o que suscitou quinze estudos.

A partir da análise, levantamos que as pesquisas estão concentradas na região Sudeste, são em sua maioria dissertações e há um indício de crescimento dos estudos nos últimos cinco anos. Além disso, quanto aos objetivos de pesquisa, notamos que mesmo as pesquisas envolverem sujeitos crianças, há forte influência de atingir discussões voltadas para o campo de ensino.

No que se refere às metodologias de ensino, o uso de atividades com uma perspectiva voltada para análise do pensamento numérico tem a sua maior evidência. Já sobre as metodologias de pesquisa, o estudo de caso apresenta-se como a opção mais frequente de intervenção. No que tange as inferências, notamos que muitas ainda são genéricas e com poucas considerações sobre o conceito de número. 
Por fim, esperamos que este estudo possibilite outros pesquisadores estruturarem suas pesquisas e produzirem novas intervenções sobre o conceito de número com crianças da Educação Infantil e Anos Iniciais do Ensino Fundamental.

\section{Referências}

ALEIXO, H. P. A construção do conceito de número por uma aluna com surdocegueira congênita. Orientadora: Thaís Philipsen Grützmann. 2018. 181 f. Dissertação (Mestrado em Educação Matemática) - Programa de Pós-Graduação em Educação Matemática, Universidade Federal de Pelotas, Pelotas, RS, 2018. Disponível em: http://guaiaca.ufpel.edu.br:8080/handle/prefix/6565. Acesso em: 30 set. 2021.

BARDIN, L. Análise de Conteúdo. São Paulo: Edições 70, 2011.

BELO, P. A. P. A aprendizagem do conceito de número de crianças do Infantil V: interações com o flex memo. Orientador: Paulo Meireles Barguil. 2018. 165f. Dissertação (Mestrado em Educação) - Programa de Pós-Graduação em Educação, Universidade Federal do Ceará, Fortaleza, CE, 2018. Disponível em: http://www.repositorio.ufc.br/handle/riufc/39404. Acesso em: 30 set. 2021.

BINSFELD, C. D.; GOLIN, A. L.; KLEIN, M. L. Correspondência um a um: uma situação desencadeadora de aprendizagem voltada ao conceito de número. In: ENCONTRO NACIONAL DE EDUCAÇÃO MATEMÁTICA, 13., 2019, Cuiabá, MT. Anais [...]. SBEM Regional Mato Grosso, 2019.

BONALDO, I. M. Investigações sobre números naturais e processos de ensino e aprendizagem desse tema no início da escolaridade. Orientadora: Celia Maria Carolino Pires. 2007. 176 f. Dissertação (Mestrado em Educação) - Pontifícia Universidade Católica de São Paulo, São Paulo, 2007. Disponível em: https://tede2.pucsp.br/handle/handle/11508. Acesso em: 30 set. 2021.

BOSCARIOL, F. Uma proposta de software de educação matemática para educação infantil. Orientadora: Afira Vianna Ripper. 2004. 73f. Dissertação (Mestrado em Educação) - Universidade Estadual de Campinas, Faculdade de Educação, Campinas, SP, 2004. Disponível em: http://repositorio.unicamp.br/jspui/handle/REPOSIP/253242. Acesso em: 30 set. 2021.

DEHAENE, S. The number sense: How the mind creates mathematics. New York: Oxford University Press, 1997.

DINIS, A. C. Representação Semiótica: uma perspectiva para a construção do conceito de número na Educação Infantil. 2018. 191f. Dissertação (Mestrado em Educação, Cultura e Comunicação) - Universidade do Estado do Rio de Janeiro, Rio de Janeiro, 2018.

FERNANDES, F. A.; MORAES, J. C. P. de; PEREIRA, A. L. Adolescentes em conflito com a lei nas pesquisas em Educação: um olhar a partir de dissertações e teses. Revista Educar Mais, Pelotas, RS, v. 4, n. 3, p. 773-793, 2020. DOI: https://doi.org/10.15536/reducarmais.4.2020.2045.

FERRARI, A. H. O senso numérico da criança: formação e características. Orientadora: Sonia Barbosa Camargo Igliori. 2008. 189 f. Tese (Doutorado em Educação) - Pontifícia Universidade Católica de São Paulo, São Paulo, 2008. Disponível em: https://tede2.pucsp.br/handle/handle/11357. Acesso em: 30 set. 2021. 
FONSECA, R. F. da. Número: o conceito a partir de jogos. Orientadora: Sonia Barbosa Camargo Igliori. Coorientador: Michael Otte. 2005. 96 f. Dissertação (Mestrado em Educação) Pontifícia Universidade Católica de São Paulo, São Paulo, 2005. Disponível em: https://tede2.pucsp.br/handle/handle/11001. Acesso em: 30 set. 2021.

GRANDO, R.C. O jogo e suas possibilidades metodológicas no processo ensino aprendizagem da matemática. Orientador: Sérgio Lorenzato. 1995. 175f. Dissertação (Mestrado em Educação) Universidade de Campinas, Campinas, SP, 1995. Disponível em: http://repositorio.unicamp.br/jspui/handle/REPOSIP/253786. Acesso em: 30 set. 2021.

GUILLEN, J. D.; SOUSA, M. C. Percepções de crianças do $1^{\circ}$ Ano do Ensino Fundamental sobre o conceito de números. In: ENCONTRO NACIONAL DE EDUCAÇÃO MATEMÁTICA, 10., jul. 2010, Salvador, BH. Anais [...]. Salvador: SBEM, 2010. Disponível em: https://atelierdigitas.net/CDS/ENEM10/artigos/CC/T3 CC163.pdf.

LORENZATO, S. Educação Infantil e percepção matemática. Campinas: Autores Associados, 2008.

MADALENA, S. P. Investigação da Construção do Número em LIBRAS: estudo com crianças surdas. Orientadora: Jane Correa. 2017. 232f. Tese (Doutorado em Psicologia) - Universidade do Rio de Janeiro, Rio de Janeiro, 2017. Disponível em:

https://sucupira.capes.gov.br/sucupira/public/consultas/coleta/trabalhoConclusao/viewTrabalhoCo nclusao.jsf?popup=true\&id trabalho=5220602.

MORAES, J. C. P. Jogos Abacus e Composição e o sistema posicional para alunos surdos: olhares de professores num curso de libras. Ensino da Matemática em Debate, São Paulo, SP, v. 4, n. 2, p. 87-105, 2017. Disponível em: https://revistas.pucsp.br/index.php/emd/article/view/32879. Acesso em: 30 set. 2021.

NOLETO, C. A. S. A construção do número pela criança com deficiência intelectual: a percepção entre diferentes ambientes escolares. Orientador: Cristiano Alberto Muniz. 2017. 148f. Dissertação (Mestrado em Educação) - Universidade de Brasília, Brasília, 2017. Disponível em: https://repositorio.unb.br/handle/10482/23935. Acesso em: 30 set. 2021.

ROMANOWSKI, J. P.; ENS, R. T. As pesquisas denominadas do tipo "estado da arte" em educação. Revista Diálogo Educacional, Curitiba, PR, v. 6, n. 19, p. 37-50, set./dez. 2006. Disponível em: https://periodicos.pucpr.br/index.php/dialogoeducacional/article/view/24176. Acesso em: 30 set. 2021.

SANTOS, B. M. dos; MANFREDO, E. C. G; COSTA, E. M. P. da. Análises no processo de construção do conceito de número de alunos do $1^{\circ}$ Ano do Ensino Fundamental em uma prática colaborativa. In: ENCONTRO NACIONAL DE EDUCAÇÃO MATEMÁTICA, 13., 2019, Cuiabá, MT. Anais [...]. Cuiabá: SBEM, 2019. Disponível em:

https://sbemmatogrosso.com.br/xiiienem/anais.php.

SILVA, J. E. F. da. Uma proposta para utilização do computador no processo de ensino e aprendizagem dos primeiros números do sistema hindu-arábico. Orientadora: Maria Lucia Lorenzetti Wodewotzky. 1998. 151f. Dissertação (Mestrado em Educação Matemática) - Programa de Pós-Graduação em Educação Matemática, Universidade Estadual Paulista, Rio Claro, SP, 1998. Disponível em: https://repositorio.unesp.br/handle/11449/124141. Acesso em: 30 set. 2021.

SOUZA, M. B. de. O ensino do conceito de número: objetivações nas proposições davydovianas e formalista moderna. Orientador: Ademir Damazio. 2013. 237f. Dissertação (Mestrado em Educação) - Programa de Pós-Graduação em Educação, Universidade do Extremo 
Sul Catarinense, Criciúma, SC, 2013. Disponível em: http://repositorio.unesc.net/handle/1/1761. Acesso em: 30 set. 2021.

YOKOYAMA, L. A. Uma Abordagem Multissensorial para o desenvolvimento do conceito de número natural em indivíduos com síndrome de Down. Orientadora: Siobhan Victoria Healy. 2012. 230f. Tese (Doutorado em Educação Matemática) - Pós-Graduação Strictu Sensu em Educação Matemática, Universidade Bandeirante de São Paulo, São Paulo, SP, 2012. Disponível em: https://repositorio.pgsskroton.com//handle/123456789/3484. Acesso em: 30 set. 2021. 